\title{
Chronic alcohol ingestion exacerbates lung epithelial barrier dysfunction in HIV-1 transgenic rats
}

\author{
Xian Fan ${ }^{1,2}$, Pratibha C. Joshi ${ }^{1,2}$, Michael Koval ${ }^{2}$, and David M. Guidot ${ }^{1,2}$ \\ 1 Pulmonary Section, Atlanta VAMC, Atlanta, GA 30322 \\ 2 Division of Pulmonary, Allergy \& Critical Care Medicine, Emory University School of Medicine, \\ Atlanta, GA 30322
}

\section{Abstract}

Background-Alcohol abuse and HIV-1 infection frequently co-exist and these individuals are at high risk for serious lung infections and respiratory failure. Although alcohol ingestion and HIV-1 transgene expression have been shown to independently cause oxidative stress and disrupt alveolar epithelial barrier function in experimental models, their interactive effects have not been examined.

Methods and Results-In this study we determined that chronic alcohol ingestion (12 wks) exacerbated the already significant defects in alveolar epithelial paracellular permeability and lung liquid clearance in HIV-1 transgenic rats. Further, immunocytochemical analyses of tight junction protein expression in primary alveolar epithelial cells showed that occludin and zonula occludens-1 (ZO-1) localization within the plasma membrane was more disrupted than in either condition alone, consistent with the observed defects in epithelial barrier function. Interestingly, expression of $\mathrm{Nrf} 2$, the transcription factor required to activate the antioxidant response element, was decreased in primary alveolar epithelial cells isolated from HIV-1 transgenic rats. In parallel, exposing lung epithelial cells in vitro to either alcohol or the HIV-related protein gp120 also decreased Nrf2 expression. Importantly, treatment with procysteine, which increases thiol antioxidants including glutathione, improved tight junction protein localization in the plasma membrane and restored alveolar epithelial barrier function in alcohol-fed HIV-1 transgenic rats.

Conclusions-These results provide novel evidence that HIV-related proteins and alcohol together causes more barrier dysfunction in the lung epithelium than either stress alone. However, these significant effects on the alveolar barrier can be mitigated by augmenting the thiol antioxidant pool, a strategy with potential clinical applications in subjects who are highly vulnerable to lung disease because of co-existent alcohol abuse and HIV infection.

\section{Keywords}

alveolar barrier function; tight junction proteins; Nrf2; procysteine; glutathione

\section{INTRODUCTION}

Although the introduction of highly active antiretroviral viral therapy (HAART) has dramatically changed the natural history of HIV/AIDS, lung complications remain a major cause of morbidity and the leading cause of mortality in this disease (Afessa et al., 1998). Unfortunately, even relatively effective suppression of viral replication may be insufficient

Corresponding author: Xian Fan, MD, Division of Pulmonary, Allergy \& Critical Care Medicine, Emory University School of Medicine, 615 Michael Street, Suite 205, Atlanta, GA 30322, Tel: (404) 727-3026, Fax: (404) 712-2974, xfan@emory.edu. 
to preserve overall health in infected individuals, as some manifestations of HIV-1 infection do not correlate directly with the viral titers. There is growing evidence that HIV-1-related proteins such as Tat and gp-120 are directly toxic to cells that are not infected by the virus itself and contribute to a variety of HIV-associated disorders such as dementia (Kanmogne et al., 2002;Kanmogne et al., 2005). Previously we determined that transgenic expression of the HIV-1 genome in rodents, in which there is no viral replication or activation but in which HIV-1-related proteins including Tat and gp120 circulate (Joshi et al., 2008), causes significant oxidative stress, glutathione depletion, and epithelial barrier dysfunction in the alveolar space (Lassiter et al., 2009). These findings are consistent with the much earlier clinical observation that HIV-1 infection causes progressive glutathione depletion in humans (Pacht et al., 1997).

In addition, our research group has determined in both experimental rodent models as well as in clinical studies that chronic alcohol ingestion also causes oxidative stress and alveolar epithelial barrier dysfunction (Moss et al., 2000; Guidot et al., 2000;Holguin et al., 1998), and increases the risk of acute lung injury following acute insults such as sepsis or trauma (Velasquez et al., 2002;Moss et al., 2003). Although there are undoubtedly multiple mechanisms by which alcohol abuse and HIV-1 infection renders the lung epithelium susceptible to injury, a specific target that is a likely contributor is the tight junction complex that mediates epithelial permeability. HIV-1-related viral proteins and alcohol affect the blood-brain barrier as well as the lung's blood-air barrier function via oxidative stress-induced alteration of tight junction proteins (Price et al., 2005;Fernandez et al., 2007; Toborek et al., 2005). These effects on tight junctions appear to be mediated at least in part through oxidative stress, as treatment with glutathione or a glutathione precursor prevents tissue injury in the epithelium of the lung (Guidot et al., 2000), the retina (Sternberg, Jr. et al., 1993) and the intestine (Lash et al., 1986).

There is evidence that alcohol abuse exacerbates the consequences of HIV-1 infection; for example, it appears to accelerate the development of AIDS-related neuropathogenesis (Shiu et al., 2007). Unfortunately, alcohol abuse is common among individuals who are infected with HIV-1 and is associated with poorer outcomes (Shaffer et al., 2004;Braithwaite et al., 2007; Conigliaro et al., 2004;Justice et al., 2006). However, whether chronic alcohol ingestion exacerbates HIV-1-induced alveolar oxidative stress and lung epithelial barrier dysfunction has not been examined.

Within the alveolar space as in any tissues, the ability to withstand an oxidative stress depends on the induction of nuclear factor-erythroid 2-related factor 2 (Nrf2), the master transcriptional factor that activates the antioxidant response element (ARE), leading to a programmatic production of multiple antioxidants including glutathione, which is a critical antioxidant within the alveolar space. Experimentally, Nrf2 deficiency exacerbates cigarette smoke-induced emphysema in mice (Rangasamy et al., 2004), and Nrf2 protects against alcohol-induced liver injury (Lamle et al., 2008). However, even though both chronic alcohol ingestion and HIV-1-related proteins cause oxidative stress and glutathione depletion within the alveolar space, their effects on Nrf2 expression in the alveolar epithelium have not been investigated.

In this study, we used the HIV-1 transgenic rat model to investigate the effects of chronic alcohol ingestion and HIV-related proteins on alveolar epithelial barrier function and Nrf2 expression. In parallel, we evaluated whether or not preserving the glutathione pool within the alveolar space could mitigate the effects of chronic alcohol ingestion and HIV-1-related protein expression on the alveolar epithelial barrier. We report here that chronic alcohol ingestion and HIV-1 transgene expression independently inhibit Nrf2 expression, and in combination induce more barrier dysfunction than either stress alone. Importantly, 
supplementing the diet with the glutathione precursor procysteine normalized alveolar epithelial barrier function even when chronic alcohol ingestion was superimposed on HIV-1 transgene expression, suggesting a potential therapeutic strategy in the clinical setting for high-risk individuals.

\section{MATERIALS AND METHODS}

\section{Animal model}

Male HIV-1 transgenic (Fischer 344 background) (Reid et al., 2004;Reid et al., 2001) rats and Fischer 344 (wild type) were purchased from Harlan (Indianapolis, Indiana) and bred in house as we have published previously (Lassiter et al., 2009). HIV-1 transgenic and littermate wild type male rats ( $7-9$ months old when the HIV-1 Tg rats developed many clinic manifestation of AIDS) were fed the Lieber-DeCarli liquid diet (Research Diets, New Brunswick, NJ) containing either alcohol (36\% of total calories) or an isocaloric substitution with maltin-dextrin ad lib for 12 wks as previously published (Joshi et al., 2005). In some experiments, alcohol-fed HIV-1 transgenic rats had the liquid diet supplemented with procysteine, which we have previously shown preserves the glutathione pool within the alveolar space of alcohol-fed rats (Guidot et al., 2000; Velasquez et al., 2002), at a final concentration of $0.35 \%$. All procedures were approved by the Institutional Animal Care and Use Committee at the Atlanta VA, and the breeding and care of animals was supervised by the staff of the Animal Facility at that institution.

\section{Determination of alveolar epithelial barrier function, as reflected by lung liquid clearance, in vivo}

This is a standard technique that we have used previously to evaluate alveolar epithelial barrier function in vivo (Lassiter et al., 2009; Pelaez et al., 2010). Briefly, after the rats were anesthetized with sodium pentobarbital and a tracheostomy cannula placed, $2 \mathrm{ml}$ of saline $(0.9 \%)$ solution was instilled into the trachea and the rats were mechanically ventilated with room air (tidal volume of $2.5 \mathrm{cc}$ at 60 breaths/min). After $30 \mathrm{~min}$ the lung was excised and immediately weighed to obtain the wet weight, and then dehydrated overnight at $70^{\circ} \mathrm{C}$ and the dry weight determined. The wet:dry ratio for each lung sample reflects the relative amount of lung liquid clearance. As the baseline wet:dry ratio of the rat lung is $\sim 4.5$, the data were plotted relative to this baseline.

\section{Alveolar epithelial cell isolation and culture}

Alveolar epithelial cells (AECs) were isolated from HIV-1 transgenic and wild type rats using a previously described protocol (Fernandez et al., 2007;Lassiter et al., 2009). For epithelial permeability measurements, ACEs were plated onto permeable membranes $(0.4$ $\mu \mathrm{M}$ pore, Corning Corp, Lowell, MA) and cultured for a total of 7 days. In some experiments, L2 cells (ATCC CCL-149, a rat lung epithelial cell line) were treated with alcohol $(0.1 \% \mathrm{w} / \mathrm{v}) \pm$ the HIV-related protein gp120 $(100 \mathrm{ng} / \mathrm{ml})$ to determine the direct effects of these exposures on the expression of Nrf2 in these cells. The medium (DMEM/ F12 for AECs and F12K for L2 cells) was changed every other day.

\section{Determination of alveolar epithelial barrier function in vitro}

The barrier function of AEC monolayers was determined by two complementary methods; paracellular permeability to a small molecule and transepithelial electrical resistance (TEER). Permeability was determined by adding ${ }^{14} \mathrm{C}$-sucrose or FITC-Dextran $(4 \mathrm{kD})$ to the top of transwells that contained the media covering the apical surfaces of the cultured cells and 2-3 hours later, quantifying the percentage of ${ }^{14} \mathrm{C}$-sucrose or FITC-Dextran that traversed the epithelial barrier using a liquid scintillation analyzer (Packard Tri-CARB 
2500) or Bio Assay Reader (Perkin-Elmer HTS 700 plus). TEER of alveolar epithelial monolayers was determined using an EVOM volt/ohm meter with STX2 electrodes (World Precision Instruments, Sarasota, FL) as described in (Kaneda et al., 2006). Prior to the measurement, the culture medium was replaced to pre-warmed $\left(37^{\circ} \mathrm{C}\right)$ serum-free fresh culture medium. The TEER value $\left(\mathrm{ohms} \cdot \mathrm{cm}^{2}\right)$ for each monolayer was subtracted from the TEER of a blank well and multiplied by the surface area of the transwell insert.

\section{Western analyses of tight junction proteins and Nrf2}

Primary epithelial cells or L2 cells were lysed in Triton X-100 lysis buffer (25 mM Hepes/ $\mathrm{NaOH}$ (pH7.4), $150 \mathrm{mM} \mathrm{NaCl}, 4 \mathrm{mM} \mathrm{Na} 2$ EDTA, $25 \mathrm{mM} \mathrm{NaF}, 1 \%$ Triton X-100, $1 \mathrm{mM}$ $\mathrm{Na}_{3} \mathrm{VO}_{4}, 1 \mathrm{mM}$ PMSF and proteinase inhibitor cocktail (Roche Diagnostics, Mannheim, Germany) for $30 \mathrm{~min}$ on ice. All samples were spun at 10,000 $\mathrm{g}$ for $10 \mathrm{~min}$ and the supernatant (reflecting the relative non-membrane fraction) was collected for measurement of Nrf2 expression. The cell pellets (reflecting the membrane fraction) were re-suspended in SDS lysis buffer (25 mM Hepes/ $\mathrm{NaOH}$ (pH7.4), 4mM Na 2 EDTA, $25 \mathrm{mM} \mathrm{NaF} .1 \%$ SDS, $1 \mathrm{mM} \mathrm{Na}_{3} \mathrm{VO}_{4}$ ), sonicated, boiled for $5 \mathrm{~min}$ and centrifuged for $10 \mathrm{~min}$ at $14,000 \times \mathrm{g}$ for measurement of tight junction protein expression. The protein concentrations were determined by the BCA method (Thermo Scientific, Waltham, MA). An equal amount of protein $(15-30 \mu \mathrm{g})$ was separated on $8 \%$ SDS polyacrylamide gel and transferred to PVDF membrane. After blocking with 5\% milk/TBST, the membrane was incubated with antibodies for zonula occludens (ZO-1, ZO-2 or ZO-3) occludin (Invitrogen, Carlsbad, CA) or Nrf2 (Santa Cruz Biotechnology, Inc., Santa Cruz, CA) overnight and then a corresponding HRP-conjugated second antibody was added prior to SuperSignal West Pico Chemiluminescent substrate (Pierce Biotechology, Rockford, IL). The immunoreactive bands were captured with a ChemiDoc XRS system (Bio-Rad, Herclues, CA). The same membrane was stripped and incubated for anti-actin antibody (Santa Cruz biotechnology, Inc). The relative densitometry of the protein of interest in each experiment was normalized to the densitometry of the actin band.

\section{Immunocytochemistry of alveolar epithelial monolayers for tight junction protein (occludin and ZO-1) localization to the plasma membrane}

Primary AECs were cultured on glass coverslips for 7 days (Fernandez et al., 2007). Briefly, the monolayers were fixed and permeabilized with methanol/acetone and then incubated with PBS $+0.5 \%$ Triton X-100 + 3\% BSA. The primary antibody to either occludin or ZO-1 diluted in PBS $+3 \%$ BSA was added on cell layers for $1 \mathrm{hr}$ at room temperature prior incubation with Cy2-conjugated goat anti-rabbit IgG. The images were captured using an Olympus IX-70 inverted fluorescence microscope outfitted with a Hamamatzu Orca chargecoupled device.

\section{Real-time PCR to quantify the relative gene expression of tight junction proteins and Nrf2}

Total RNA was isolated from primary AECs and L2 cells and RT-PCR analysis was carried out as we have previously described (Lassiter et al., 2009). Briefly, real-time iQ SYBR Green SuperMix reagent (Bio-Rad) was mixed with cDNA (1:10 dilution) plus specific primers and the reaction was run at $95^{\circ} \mathrm{C}, 10^{\prime \prime} ; 60^{\circ} \mathrm{C}, 10^{\prime \prime}$ and $72^{\circ} \mathrm{C}, 10^{\prime \prime}$ for 40 cycles. Relative expression of the tight junction proteins occludin, ZO-1, ZO-2, and ZO-3, as well as for Nrf2 was assessed. For rat ZO-2, forward and reverse primers were 5'-GCA TGA GGA GAG CAT AAG GA-3' AND 5'-GCA GAG AGG TTT GAC TTG GA-3', respectively, creating a product of $177 \mathrm{bp}$. A $108 \mathrm{bp}$ amplicon of rat ZO-3 was generated from forward primer 5'-TGG CAT AGC TGT GTC TGG AG-3' and reverse primer 5'-ATG TGG TCC CCA GTC TGA AG-3'. The primers for rat ZO-1, occludin, Nrf2 and S9 were taken from published studies including ours (Fernandez et al., 2007; Cortese et al., 2008; Nisbet et al., 2010). All standards (1:10-1:10,000 dilution) and samples were run in 
triplicate. The PCR products of genes interested were normalized with the housekeeper gene for the ribosomal 9S from the same sample, and represented as the percentage change compared to the control for each group (untreated AEC's from wild type rats or untreated L2 cells). The PCR efficiency was $>95 \%$ for all genes analyzed.

\section{Statistics}

One-way analyses of variance were performed by Student-Newman-Keuls post-hoc tests or student T-test using Prism (GraphPad, San Diego, CA). Significance was accepted at P < 0.05 .

\section{RESULTS}

HIV-1 transgene expression impairs alveolar epithelial barrier function and increases paracellular permeability to macromolecules

We had previously determined that alveolar epithelial monolayers derived from HIV-1 transgenic rats had increased paracellular permeability to radiolabeled sucrose (Lassiter et al., 2009). Here we further characterized this defect and measured alveolar epithelial monolayers for differences in both TEER and paracellular flux of a macromolecular tracer, FITC-dextran $(4 \mathrm{kD})$. As shown in Figure 1, both TEER and FITC-dextran flux showed that there was a roughly $50 \%$ decrease $(\mathrm{P}<0.05)$ in paracellular barrier function for alveolar epithelial monolayers derived from HIV-1 transgenic rats as compared to monolayers derived from wild type rats. Thus, HIV-1 transgene expression impairs the ability of the alveolar epithelium to restrict the paracellular passage of macromolecules in addition to ions and small molecules.

\section{Chronic alcohol ingestion exacerbates barrier dysfunction in alveolar epithelial monolayers derived from HIV-1 transgenic rats}

Previously we reported that either chronic HIV-1-related protein expression or chronic alcohol ingestion could independently impair alveolar epithelial barrier function (Fernandez et al., 2007;Guidot et al., 2000;Lassiter et al., 2009). We speculated that chronic alcohol ingestion could further impair alveolar epithelial barrier function in HIV-1 transgenic rats (as a model of alcohol abuse in HIV-1-infected individuals). We first determined the effects of chronic alcohol ingestion on the ability of AECs freshly isolated from HIV-1 transgenic rats to form tight monolayers in culture. As shown in Figure 2, alveolar epithelial monolayers derived from wild type rats formed relatively tight monolayers, as reflected by a low $(\sim 3 \%)$ flux of radiolabeled sucrose across the monolayers in 2 hours. In contrast, and consistent with our previously published studies, alveolar epithelial monolayers derived from either wild type rats fed the alcohol diet or from HIV-1 transgenic rats were significantly $(\mathrm{P}<0.05)$ more permeable than monolayers derived from wild type rats. Further, alveolar epithelial monolayers derived from HIV-1 transgenic rats fed the alcohol diet were even more permeable $(\mathrm{P}<0.05)$ than monolayers derived from either wild type rats fed the alcohol diet or from HIV-1 transgenic rats.

\section{Chronic alcohol ingestion or HIV-1 transgene expression altered the expression of occludin and zonula occludens (tight junction proteins) in cultured alveolar epithelial monolayers, but there was no evidence that these effects were additive}

Alveolar epithelial barrier function is critically dependent on tight junction formation and function. As we had previously determined that either chronic alcohol ingestion or HIV-1 transgene expression alters the expression and membrane localization of key tight junction proteins in the alveolar epithelium (Fernandez et al., 2007; Lassiter et al., 2009), we next examined the expression the tight junction proteins occludin and ZO-1, ZO-2 and ZO-3. As 
shown in Figure 3, panel A, the relative gene expression of occludin and ZO-1 was significantly $(\mathrm{P}<0.05)$ albeit not dramatically decreased by either alcohol ingestion or by HIV-1 transgene expression. In contrast, gene expression of ZO-2 and ZO-3 were not affected $(\mathrm{P}>0.05)$ by either alcohol ingestion or HIV-1 transgene expression. Only occludin expression was decreased more $(\mathrm{P}<0.05)$ by both alcohol ingestion and HIV-1 transgene expression than by either stress alone but again, this appeared to be a modest additive effect. In contrast, and as shown in Figure 3, panel B, alcohol ingestion or HIV-1 transgene significantly decreased the protein expression of occludin, ZO-1, ZO-2, and ZO-3 within the membrane fractions of the alveolar epithelial cells; the sole exception being that ZO-3 protein was not decreased $(\mathrm{P}>0.05)$ by HIV-1 transgene expression alone. However, there was no evidence that the combination of alcohol ingestion and HIV-1 transgene expression had any additive effects on the protein expression of any of the tight junction proteins examined. Overall, although alcohol ingestion and/or HIV-1 transgene expression decreased the expression of these four tight junction proteins, these effects were quite modest and by themselves are unlikely to explain the epithelial barrier dysfunction shown in Figure 1 and 2.

\section{In contrast, chronic alcohol ingestion or HIV-1 transgene expression altered the membrane localization of occludin and zonula occludens- 1 in cultured alveolar epithelial monolayers}

Tight junctions must be localized to the plasma membrane (and oriented properly) for them to regulate the epithelial barrier. As western analyses only reflect the quantity of protein expressed and not the localization of these proteins, we next investigated how alcohol ingestion \pm HIV-1 transgene expression affected the membrane localization of occludin and ZO-1 in the alveolar epithelial monolayers by immunocytochemistry. As shown in Figure 4, alcohol ingestion or HIV-1 transgene expression independently caused obvious defects shown as less uniform and punctuate staining (arrows) in the membrane localization of occludin (panel A) and of ZO-1 (panel B) as determined by immunocytochemistry. Even more pronounced were the combined effects of alcohol ingestion and HIV-1 transgene expression as evidenced by a dramatic loss of occludin and ZO-1 staining in the cell-cell borders (arrowhead) in the lower right image in each panel. Therefore, even though protein expression (by western analysis) of these tight junction proteins was not dramatically affected by alcohol and HIV-1 trangene expression (Figure 3), the localization of these proteins to the plasma membrane was profoundly impaired.

\section{Dietary supplementation with the glutathione precursor procysteine restored alveolar epithelial barrier function in alcohol-fed HIV-1 transgenic rats}

As shown in Figure 2, the combination of HIV-1-related protein expression and alcohol ingestion in vivo caused a greater permeability defect in alveolar epithelial monolayers derived from these animals and analyzed in vitro than did either stress alone. It has been shown that dietary supplementation with the glutathione precursor procysteine preserves alveolar epithelial barrier function in alcohol-fed rats (Guidot et al., 2000). We examined if procysteine could improve barrier function when both chronic stresses were present. In these experiments we assessed alveolar epithelial barrier function by measuring the transepithelial electric resistance (TEER). As shown in Figure 5, panel A, alcohol ingestion and HIV-1 transgene expression each independently decreased $(\mathrm{P}<0.05)$ the TEER in the epithelial monolayers, and the combination trended to further decrease TEER; however, in these studies the combination did not cause a significant decrease $(\mathrm{P}>0.05)$ compared to either stress alone. Importantly, alveolar epithelial monolayers derived from alcohol-fed HIV-1 transgenic rats whose diets were supplemented with procysteine had significantly increased $(\mathrm{P}<0.05)$ TEER's than even monolayers from wild type rats (Figure 5, panel A). To determine whether the effects on alveolar epithelial barrier function in vitro correlated with alveolar epithelial barrier function in vivo, we next determined lung liquid clearance of an intratracheal saline challenge. We have shown in multiple previous publications that lung 
liquid challenge not only correlates with epithelial permeability in vitro, but also that each index of barrier function is impaired by either alcohol ingestion alone or HIV-1 transgenic expression alone (Guidot et al., 2000;Pelaez et al., 2004;Lassiter et al., 2009). As shown in Figure 5, panel B, lung liquid clearance was decreased $(\mathrm{P}<0.05$, as reflected by an increased wet:dry ratio in the lung tissue following the saline challenge) in wild type rats fed the alcohol diet and in HIV-1 transgenic rats. Interestingly, HIV-1 transgenic rats fed the alcohol diet had significantly decreased $(\mathrm{P}<0.05)$ lung liquid clearance than either wild type rats fed the alcohol diet or HIV-1 transgenic rats. In contrast, HIV-1 transgenic rats fed the alcohol diet but supplemented with procysteine had the same $(\mathrm{P}>0.05)$ lung liquid clearance as wild type rats, suggesting that procysteine completely prevented the additive effects of these two stresses on alveolar epithelial barrier function in vivo.

\section{Dietary supplementation with procysteine qualitatively improved the membrane localization of occludin and zonula occludens- 1 in cultured alveolar epithelial monolayers from alcohol-fed rats \pm HIV-1 transgene expression}

As dietary procysteine restored alveolar epithelial barrier function in alcohol-fed HIV-1 transgenic rats, we determined whether or not these salutary functional effects could be explained by any improvements in tight junction protein insertion into the plasma membrane. As shown in Figure 6, dietary procysteine qualitatively improved the membrane localization of occludin (panel A) and ZO-1 (panel B) in alveolar epithelial monolayers derived from both wild type and HIV-1 transgenic rats fed the alcohol diet, which restored more uniform, continuous staining on the cell membrane compare to that from alcohol fed rat. Therefore, dietary supplementation with procysteine, a glutathione precursor that we previously showed restores alveolar epithelial barrier function in alcohol-fed rats (Guidot et al., 2000), improves tight junction protein expression in the plasma membrane and normalizes alveolar epithelial barrier function even when the stress of chronic alcohol ingestion is superimposed upon HIV-1 transgene expression.

\section{Alcohol and HIV-1-related proteins inhibit the expression of Nrf2, the transcription factor that activates the antioxidant response element (ARE) during oxidative stressed}

The beneficial effects of dietary procysteine are consistent with the wealth of experimental evidence that chronic alcohol ingestion and HIV-1 infection (in part through HIV-1-related proteins including Tat and gp120) cause oxidative stress in target tissues such as the lung. Under healthy conditions, cells respond to oxidative stress by activating the antioxidant response element (ARE), a genetic program that is turned on by the transcription factor Nrf2 and ultimately increases the production of multiple antioxidants including glutathione. Therefore, one might predict that Nrf2 expression should increase in the face of the oxidative stress caused by alcohol and/or HIV-1-related protein expression. However, as shown in Figure 7, panel A, chronic alcohol ingestion \pm HIV -1 transgene expression significantly decreased $(\mathrm{P}<0.05) \mathrm{Nrf} 2$ gene expression $\sim 30 \%$ (as determined by quantitative PCR) in alveolar epithelial cells freshly isolated from these rats. To verify if alcohol and/or HIV-1-related proteins could directly inhibit Nrf2 expression in lung epithelial cells, we measured Nrf2 gene expression in rat lung epithelial cell line, L2 cells that were exposed to alcohol \pm the HIV-1-related protein gp120 in vitro for 3 days. As shown in Figure 7, panel B, these treatments also significantly $(\mathrm{P}<0.05)$ decreased Nrf2 expression by $\sim 25 \%$, which is consistent with the effects in vivo as shown in panel A. To verify that alcohol and/or gp120 had significant inhibitory effects on Nrf2 protein levels, we quantified Nrf2 protein in these L2 cells. As shown in Figure 8, alcohol exposure, or alcohol + gp120 exposure, significantly $(\mathrm{P}<0.05)$ decreased Nrf2 protein levels by $\sim 30 \%$; in these experiments, gp120 treatment showed a trend toward decreased Nrf2 protein levels, but this effect did not achieve significance at the $\mathrm{P}<0.05$ level. Overall, the data shown in Figure 7 and Figure 8 demonstrate that despite the oxidative stress within the alveolar space, Nrf2 expression is 
actually inhibited by alcohol and/or HIV-1-related proteins, suggesting that the lung epithelium is unable to mount an appropriate antioxidant defense.

\section{DISCUSSION}

In this study we determined that chronic alcohol ingestion exacerbated the alveolar epithelial barrier dysfunction caused by chronic HIV-1-related protein expression. Specifically, prolonged alcohol ingestion decreased alveolar epithelial barrier function in HIV-1 transgenic rats in vivo, as reflected by decreased liquid clearance of an intratracheal saline challenge. In parallel, cultured alveolar epithelial cell monolayers derived from alcohol-fed HIV-1 transgenic rats had increased paracellular permeability to sucrose compared to monolayers from alcohol-fed wild type rats and from HIV-1 transgenic rats not fed alcohol. Alveolar epithelial barrier dysfunction correlated with alterations in the expression of the tight junction proteins occludin and ZO-1. In particular, although the expression of these proteins was either unchanged or mildly decreased, the membrane localization of these tight junction proteins was markedly impaired by the combination of alcohol ingestion and HIV-1 transgene expression when assessed by immunocytochemistry. These effects appeared to be mediated in part by oxidative stress as tight junction protein localization in the plasma membrane, and alveolar epithelial barrier function in vitro and in vivo, were restored by supplementing the diets of alcohol-fed transgenic rats with the glutathione precursor, procysteine. Interestingly, alcohol ingestion and HIV-1-related protein expression, alone or in combination, decreased the expression of Nrf2, providing additional evidence that an unexpected mechanism by which alcohol and HIV-1-related proteins cause oxidative stress in the lung is by directly lowering its antioxidant defenses. Taken together, these findings suggest that alcohol and HIV-1-related proteins can independently inhibit the ability of the alveolar epithelium to defend itself against oxidative stresses, which leads to derangements in tight junction protein assembly and impaired alveolar epithelial barrier function. Moreover, the combination of chronic alcohol ingestion and HIV-1-related protein expression caused worse barrier disruption than either stress alone. Fortuitously, dietary supplementation with procysteine improved membrane localization of tight junction proteins and restored alveolar epithelial barrier function, suggesting that a comparable dietary strategy could enhance lung health in the clinical setting where the combination of alcohol abuse and HIV-1 infection causes great morbidity and mortality.

These findings have important potential implications for our understanding of the mechanisms by which chronic alcohol abuse and HIV-1 infection, independently but even more so in combination, render individuals susceptible to acute lung injury. It has now been recognized for more than a decade that alcohol abuse increases the incidence of acute lung injury by 2-4-fold (Moss et al., 1996;Moss et al., 2003). Our group has shown that chronic alcohol ingestion causes previously unrecognized oxidative stress, as best reflected by severe glutathione deficiency, and epithelial barrier dysfunction in the alveolar space of experimental animals as well as in otherwise healthy human subjects (Fernandez et al., 2007; Guidot et al., 2000;Holguin et al., 1998;Moss et al., 2000;Burnham et al., 2003). In parallel, it has long been recognized that chronic HIV-1 infection causes systemic oxidative stress and glutathione depletion (Stehbens, 2004;Tang and Smit, 2000;Pacht et al., 1997). More recently, our group showed for the first time in an experimental rat model that chronic HIV-1 transgene expression causes oxidative stress, glutathione depletion, and epithelial barrier dysfunction comparable to what we had previously identified in our rat model of chronic alcohol ingestion (Lassiter et al., 2009). Unfortunately, alcohol abuse often complicates HIV-1 infection, and is associated with worse clinical outcomes in these individuals (Shaffer et al., 2004;Braithwaite et al., 2007;Conigliaro et al., 2004;Justice et al., 2006). However, to our knowledge the effects of alcohol and HIV-1 in combination on the lung have not been previously examined. As alcohol and HIV-1-related proteins have been 
shown to cause oxidative stress and cellular dysfunction in diverse cellular targets and tissues, it is not surprising that the combination of the two caused worse alveolar barrier dysfunction than either stress alone. Procysteine, which we have previously shown preserves the glutathione pool within the alveolar space and maintains normal epithelial barrier function in the setting of chronic alcohol ingestion, had remarkable salutary effects on alveolar epithelial function even when alcohol ingestion was superimposed on HIV-1 transgene expression. Although further studies are necessary to identify the discrete molecular mechanisms, our findings provide novel evidence that alcohol and HIV-1-related proteins inhibit the ability of the alveolar epithelium to defend itself against oxidative stress and as a consequence this normally tight barrier becomes dysfunctional and renders the lung susceptible to acute edematous injury.

We recognize that the rat model used in this study does not recapitulate all of the effects of HIV-1 infection in humans. Most notably, there is no viral replication in this transgenic model. However, the HIV-1-related proteins, including Tat and gp120, that are known to mediate many of the systemic effects of HIV-1 infection are expressed and cause a progressive phenotype that bears remarkable similarities to the human disease (Reid et al., 2001). For example, we previously determined that the levels of gp120 in these rats are $\sim 28$ $\mathrm{ng} / \mathrm{ml}$ in the serum and $\sim 10 \mathrm{ng} / \mathrm{ml}$ in bronchoalveolar lavage fluid at $8-10$ months of age when the systemic effects are becoming grossly apparent (Joshi et al., 2008). These plasma levels are consistent with, albeit somewhat higher than, those reported in human plasma ( 0.5 $-15.6 \mathrm{ng} / \mathrm{ml}$ ) with acute and early HIV infection (Rychert et al., 2010). Nevertheless, this transgenic model is consistent with the compelling evidence that HIV-1-related proteins including gp120 can impair blood-brain barrier function (Toneatto et al., 1999;Dallasta et al., 1999; Cioni and Annunziata, 2002) as well as intestinal mucosal epithelial barrier function (Nazli et al., 2010). In terms of blood-brain barrier dysfunction and other complications that involve endothelial damage, the presumption is that they are mediated by HIV-1-related proteins as there is no evidence that the virus can infect endothelial cells (Kanmogne et al., 2001). Consistent with our studies on the alveolar epithelial barrier, gp120-induced blood-brain barrier dysfunction is associated with fragmentation or absence of the tight junction membrane proteins occludin and ZO-1 (Dallasta et al., 1999), and the increased TEER seen in intestinal epithelial monolayers infected with HIV-1 virus can be abrogated by treatment with a gp-120 neutralizing antibody (Nazli et al., 2010). Therefore, although the transgenic rat is clearly not a model of viral infection and/or viral replication, it appears to be an excellent model to study the pathophysiological effects of HIV-1-related proteins on target tissues such as the alveolar epithelium that are not infected by the virus. In this context, our studies suggest that these proteins are responsible for the oxidative stress and glutathione deficiency in the airways of infected individuals. Whether or not HIV-1 infection impairs Nrf2 expression in the human lung epithelium as we report in the HIV-1 transgenic rat model is unknown, but this is an intriguing possibility to explain why glutathione pools are so low in these individuals.

Either directly or indirectly, this oxidative stress somehow interferes with the localization of tight junction proteins in the alveolar epithelial cell plasma membrane where they are required to form the relatively impermeable barrier that is necessary to maintain gas exchange in the lung. Tight junction proteins play critical roles in the barrier by limiting solute movement between adjacent epithelial cells and maintaining cell polarity. Our findings are consistent with a previous study in which co-treatment with HIV-1-related proteins and alcohol induced cytoskeletal reorganization and increased permeability of the endothelium that forms the blood-brain barrier (Shiu et al., 2007). In our study, we determined that although alcohol \pm HIV-1 transgene expression had only modest effects on the expression of the tight junction proteins occludin and ZO-1, these chronic stresses markedly attenuated and/or disrupted their localization to the cell-cell borders in alveolar 
epithelial monolayers. Although the mechanisms are not yet known, oxidative stress appears to mediate these effects as dietary supplementation with procysteine was associated with improved membrane localization of these tight junction proteins and, in parallel, restored alveolar epithelial barrier function.

That chronic alcohol ingestion and HIV-1 transgene expression produce additive defects in alveolar epithelial barrier function via mechanisms that are mediated by oxidative stress is not surprising, as this study builds on recent work in our laboratory in each model individually (Fernandez et al., 2007; Lassiter et al., 2009). However, it was unexpected to discover that alcohol and HIV-1-related proteins inhibit the expression of Nrf2. Specifically, $\mathrm{Nrf} 2$ is a ubiquitous transcription factor that protects cells against oxidative insults through activation of the antioxidant response element (ARE), which mediates expression of antioxidant/detoxifying enzymes and cytoprotective proteins. Therefore, in the context of the chronic oxidative stress in the lung caused by alcohol abuse and/or HIV-1 infection, Nrf2 expression should be markedly up-regulated. In contrast, we determined that Nrf2 gene expression was decreased in the alveolar epithelium of HIV-1 transgenic rats \pm alcohol ingestion in vivo, and that alcohol or the HIV-1-related protein gp120 can directly inhibit $\mathrm{Nrf} 2$ gene and protein expression in lung epithelial cells in vitro. These findings raise the intriguing possibility that alcohol abuse and HIV-1 infection cause oxidative stress within the alveolar space in part by inhibiting local antioxidant defenses. This is a highly oxidizing microenvironment even in the otherwise healthy state, and there is good evidence for the role of Nrf2 in protecting against oxidative stresses. For example, mice that lack Nrf2 expression (i.e. $\mathrm{Nrf}^{-1-}$ ) are severely susceptible to tissue and organ injury and inflammation in response to an oxidant insult (Chan and Kan, 1999; Liu et al., 2009;Reddy et al., 2009). Interestingly, there is evidence that Nrf2 expression is decreased in the lungs of individuals with chronic obstructive pulmonary disease, which is characterized by alveolar epithelial damage and loss of gas-exchange units (Malhotra et al., 2009). In contrast, enhancing expression of Nrf2 experimentally with sulforaphane significantly increases the expression of endogenous cytoprotective genes such as HO-1, NADPH:quinone oxidoreductase 1 (NQO-1), glutathione-S-transferase $\alpha 3$ (GST3 $\alpha$ ) in the brain and improves tight junction protein expression and blood-brain barrier function in a model of brain injury (Zhao et al., 2007). At present the mechanisms by which alcohol and/or HIV-1-related proteins inhibit Nrf2 expression are unknown. However, these findings provide a new insight into the oxidative stress that characterizes both of these conditions.

In summary, we report that chronic alcohol ingestion exacerbates alveolar epithelial barrier dysfunction in an experimental model of chronic HIV-1-related protein expression. Both alcohol and HIV-1-related proteins independently inhibit expression of Nrf2 and interfere with membrane localization of tight junction proteins that are necessary to form the normal alveolar epithelial barrier, and together cause greater barrier disruption than either stress alone. Importantly, dietary supplementation with the glutathione precursor procysteine improves tight junction protein localization to the plasma membrane in the alveolar epithelium and restores normal barrier function. As alcohol abuse commonly complicates HIV-1 infection and these individuals are at great risk of severe pneumonia and acute lung injury, these findings are potentially of great clinical significance. Specifically, if the results in this experimental model translate to the clinical setting, then comparable dietary supplements could improve lung health in individuals infected with HIV-1 even if they consume unhealthy amounts of alcohol.

\section{Acknowledgments}

We thank Robert Raynor and Todd Mills for their excellent technical support, and Christina Ward for her assistance with the immunocytochemistry analyses. 


\section{References}

Afessa B, Green W, Chiao J, Frederick W. Pulmonary complications of HIV infection: autopsy findings. Chest. 1998; 113:1225-1229. [PubMed: 9596298]

Braithwaite RS, Conigliaro J, Roberts MS, Shechter S, Schaefer A, McGinnis K, Rodriguez MC, Rabeneck L, Bryant K, Justice AC. Estimating the impact of alcohol consumption on survival for HIV+ individuals. AIDS Care. 2007; 19:459-466. [PubMed: 17453583]

Burnham EL, Brown LA, Halls L, Moss M. Effects of chronic alcohol abuse on alveolar epithelial barrier function and glutathione homeostasis. Alcohol Clin Exp Res. 2003; 27:1167-1172. [PubMed: 12878924]

Chan K, Kan YW. Nrf2 is essential for protection against acute pulmonary injury in mice. Proc Natl Acad Sci U S A. 1999; 96:12731-12736. [PubMed: 10535991]

Cioni C, Annunziata P. Circulating gp120 alters the blood-brain barrier permeability in HIV-1 gp120 transgenic mice. Neurosci Lett. 2002; 330:299-301. [PubMed: 12270651]

Conigliaro J, Madenwald T, Bryant K, Braithwaite S, Gordon A, Fultz SL, Maisto S, Samet J, Kraemer K, Cook R, Day N, Roach D, Richey S, Justice A. The Veterans Aging Cohort Study: observational studies of alcohol use, abuse, and outcomes among human immunodeficiency virusinfected veterans. Alcohol Clin Exp Res. 2004; 28:313-321. [PubMed: 15112939]

Cortese MM, Suschek CV, Wetzel W, Kroncke KD, Kolb-Bachofen V. Zinc protects endothelial cells from hydrogen peroxide via Nrf2-dependent stimulation of glutathione biosynthesis. Free Radic Biol Med. 2008; 44:2002-2012. [PubMed: 18355458]

Dallasta LM, Pisarov LA, Esplen JE, Werley JV, Moses AV, Nelson JA, Achim CL. Blood-brain barrier tight junction disruption in human immunodeficiency virus-1 encephalitis. Am J Pathol. 1999; 155:1915-1927. [PubMed: 10595922]

Fernandez AL, Koval M, Fan X, Guidot DM. Chronic alcohol ingestion alters claudin expression in the alveolar epithelium of rats. Alcohol. 2007; 41:371-379. [PubMed: 17889313]

Guidot DM, Modelska K, Lois M, Jain L, Moss IM, Pittet JF, Brown LA. Ethanol ingestion via glutathione depletion impairs alveolar epithelial barrier function in rats. Am J Physiol Lung Cell Mol Physiol. 2000; 279:L127-L135. [PubMed: 10893211]

Holguin F, Moss I, Brown LA, Guidot DM. Chronic ethanol ingestion impairs alveolar type II cell glutathione homeostasis and function and predisposes to endotoxin-mediated acute edematous lung injury in rats. J Clin Invest. 1998; 101:761-768. [PubMed: 9466970]

Joshi PC, Applewhite L, Ritzenthaler JD, Roman J, Fernandez AL, Eaton DC, Brown LA, Guidot DM. Chronic ethanol ingestion in rats decreases granulocyte-macrophage colony-stimulating factor receptor expression and downstream signaling in the alveolar macrophage. J Immunol. 2005; 175:6837-6845. [PubMed: 16272341]

Joshi PC, Raynor R, Fan X, Guidot DM. HIV-1-transgene expression in rats decreases alveolar macrophage zinc levels and phagocytosis. Am J Respir Cell Mol Biol. 2008; 39:218-226. [PubMed: 18314538]

Justice AC, Lasky E, McGinnis KA, Skanderson M, Conigliaro J, Fultz SL, Crothers K, Rabeneck L, Rodriguez-Barradas M, Weissman SB, Bryant K. Medical disease and alcohol use among veterans with human immunodeficiency infection: A comparison of disease measurement strategies. Med Care. 2006; 44:S52-S60. [PubMed: 16849969]

Kaneda K, Miyamoto K, Nomura S, Horiuchi T. Intercellular localization of occludins and ZO-1 as a solute transport barrier of the mesothelial monolayer. J Artif Organs. 2006; 9:241-250. [PubMed: 17171403]

Kanmogne GD, Kennedy RC, Grammas P. Analysis of human lung endothelial cells for susceptibility to HIV type 1 infection, coreceptor expression, and cytotoxicity of gp120 protein. AIDS Res Hum Retroviruses. 2001; 17:45-53. [PubMed: 11177382]

Kanmogne GD, Kennedy RC, Grammas P. HIV-1 gp 120 proteins and gp160 peptides are toxic to brain endothelial cells and neurons: possible pathway for HIV entry into the brain and HIVassociated dementia. J Neuropathol Exp Neurol. 2002; 61:992-1000. [PubMed: 12430716] 
Kanmogne GD, Primeaux C, Grammas P. HIV-1 gp120 proteins alter tight junction protein expression and brain endothelial cell permeability: implications for the pathogenesis of HIV-associated dementia. J Neuropathol Exp Neurol. 2005; 64:498-505. [PubMed: 15977641]

Lamle J, Marhenke S, Borlak J, von WR, Eriksson CJ, Geffers R, Manns MP, Yamamoto M, Vogel A. Nuclear factor-eythroid 2-related factor 2 prevents alcohol-induced fulminant liver injury. Gastroenterology. 2008; 134:1159-1168. [PubMed: 18395094]

Lash LH, Hagen TM, Jones DP. Exogenous glutathione protects intestinal epithelial cells from oxidative injury. Proc Natl Acad Sci U S A. 1986; 83:4641-4645. [PubMed: 3460063]

Lassiter C, Fan X, Joshi PC, Jacob BA, Sutliff RL, Jones DP, Koval M, Guidot DM. HIV-1 transgene expression in rats causes oxidant stress and alveolar epithelial barrier dysfunction. AIDS Res Ther. 2009; 6:1. [PubMed: 19193217]

Liu M, Grigoryev DN, Crow MT, Haas M, Yamamoto M, Reddy SP, Rabb H. Transcription factor Nrf2 is protective during ischemic and nephrotoxic acute kidney injury in mice. Kidney Int. 2009; 76:277-285. [PubMed: 19436334]

Malhotra D, Thimmulappa R, Vij N, Navas-Acien A, Sussan T, Merali S, Zhang L, Kelsen SG, Myers A, Wise R, Tuder R, Biswal S. Heightened endoplasmic reticulum stress in the lungs of patients with chronic obstructive pulmonary disease: the role of Nrf2-regulated proteasomal activity. Am J Respir Crit Care Med. 2009; 180:1196-1207. [PubMed: 19797762]

Moss M, Bucher B, Moore FA, Moore EE, Parsons PE. The role of chronic alcohol abuse in the development of acute respiratory distress syndrome in adults. JAMA. 1996; 275:50-54. [PubMed: 8531287]

Moss M, Guidot DM, Wong-Lambertina M, Ten HT, Perez RL, Brown LA. The effects of chronic alcohol abuse on pulmonary glutathione homeostasis. Am J Respir Crit Care Med. 2000; 161:414419. [PubMed: 10673179]

Moss M, Parsons PE, Steinberg KP, Hudson LD, Guidot DM, Burnham EL, Eaton S, Cotsonis GA. Chronic alcohol abuse is associated with an increased incidence of acute respiratory distress syndrome and severity of multiple organ dysfunction in patients with septic shock. Crit Care Med. 2003; 31:869-877. [PubMed: 12626999]

Nazli A, Chan O, Dobson-Belaire WN, Ouellet M, Tremblay MJ, Gray-Owen SD, Arsenault AL, Kaushic C. Exposure to HIV-1 directly impairs mucosal epithelial barrier integrity allowing microbial translocation. PLoS Pathog. 2010; 6:e1000852. [PubMed: 20386714]

Nisbet RE, Bland JM, Kleinhenz DJ, Mitchell PO, Walp ER, Sutliff RL, Hart CM. Rosiglitazone attenuates chronic hypoxia-induced pulmonary hypertension in a mouse model. Am J Respir Cell Mol Biol. 2010; 42:482-490. [PubMed: 19520921]

Pacht ER, Diaz P, Clanton T, Hart J, Gadek JE. Alveolar fluid glutathione decreases in asymptomatic HIV-seropositive subjects over time. Chest. 1997; 112:785-788. [PubMed: 9315816]

Pelaez A, Bechara RI, Joshi PC, Brown LA, Guidot DM. Granulocyte/macrophage colony-stimulating factor treatment improves alveolar epithelial barrier function in alcoholic rat lung. Am J Physiol Lung Cell Mol Physiol. 2004; 286:L106-L111. [PubMed: 14504066]

Pelaez A, Force SD, Gal AA, Neujahr DC, Ramirez AM, Naik PM, Quintero DA, Pileggi AV, Easley KA, Echeverry R, Lawrence EC, Guidot DM, Mitchell PO. Receptor for advanced glycation end products in donor lungs is associated with primary graft dysfunction after lung transplantation. Am J Transplant. 2010; 10:900-907. [PubMed: 20121754]

Price TO, Ercal N, Nakaoke R, Banks WA. HIV-1 viral proteins gp120 and Tat induce oxidative stress in brain endothelial cells. Brain Res. 2005; 1045:57-63. [PubMed: 15910762]

Rangasamy T, Cho CY, Thimmulappa RK, Zhen L, Srisuma SS, Kensler TW, Yamamoto M, Petrache I, Tuder RM, Biswal S. Genetic ablation of Nrf2 enhances susceptibility to cigarette smokeinduced emphysema in mice. J Clin Invest. 2004; 114:1248-1259. [PubMed: 15520857]

Reddy NM, Kleeberger SR, Kensler TW, Yamamoto M, Hassoun PM, Reddy SP. Disruption of Nrf2 impairs the resolution of hyperoxia-induced acute lung injury and inflammation in mice. $\mathrm{J}$ Immunol. 2009; 182:7264-7271. [PubMed: 19454723]

Reid W, Abdelwahab S, Sadowska M, Huso D, Neal A, Ahearn A, Bryant J, Gallo RC, Lewis GK, Reitz M. HIV-1 transgenic rats develop T cell abnormalities. Virology. 2004; 321:111-119. [PubMed: 15033570] 
Reid W, et al. An HIV-1 transgenic rat that develops HIV-related pathology and immunologic dysfunction. Proc Natl Acad Sci U S A. 2001; 98:9271-9276. [PubMed: 11481487]

Rychert J, Strick D, Bazner S, Robinson J, Rosenberg E. Detection of HIV gp120 in plasma during early HIV infection is associated with increased proinflammatory and immunoregulatory cytokines. AIDS Res Hum Retroviruses. 2010; 26:1139-1145. [PubMed: 20722464]

Shaffer DN, Njeri R, Justice AC, Odero WW, Tierney WM. Alcohol abuse among patients with and without HIV infection attending public clinics in western Kenya. East Afr Med J. 2004; 81:594598. [PubMed: 15868970]

Shiu C, Barbier E, Di CF, Choi HJ, Stins M. HIV-1 gp120 as well as alcohol affect blood-brain barrier permeability and stress fiber formation: involvement of reactive oxygen species. Alcohol Clin Exp Res. 2007; 31:130-137. [PubMed: 17207111]

Stehbens WE. Oxidative stress in viral hepatitis and AIDS. Exp Mol Pathol. 2004; 77:121-132. [PubMed: 15351235]

Sternberg P Jr, Davidson PC, Jones DP, Hagen TM, Reed RL, Drews-Botsch C. Protection of retinal pigment epithelium from oxidative injury by glutathione and precursors. Invest Ophthalmol Vis Sci. 1993; 34:3661-3668. [PubMed: 8258526]

Tang AM, Smit E. Oxidative stress in HIV-1-infected injection drug users. J Acquir Immune Defic Syndr. 2000; 25(Suppl 1):S12-S18. [PubMed: 11126421]

Toborek M, Lee YW, Flora G, Pu H, Andras IE, Wylegala E, Hennig B, Nath A. Mechanisms of the blood-brain barrier disruption in HIV-1 infection. Cell Mol Neurobiol. 2005; 25:181-199. [PubMed: 15962513]

Toneatto S, Finco O, van der Putten H, Abrignani S, Annunziata P. Evidence of blood-brain barrier alteration and activation in HIV-1 gp120 transgenic mice. Aids. 1999; 13:2343-2348. [PubMed: 10597775]

Velasquez A, Bechara RI, Lewis JF, Malloy J, McCaig L, Brown LA, Guidot DM. Glutathione replacement preserves the functional surfactant phospholipid pool size and decreases sepsismediated lung dysfunction in ethanol-fed rats. Alcohol Clin Exp Res. 2002; 26:1245-1251. [PubMed: 12198401]

Zhao J, Moore AN, Redell JB, Dash PK. Enhancing expression of Nrf2-driven genes protects the blood brain barrier after brain injury. J Neurosci. 2007; 27:10240-10248. [PubMed: 17881530] 


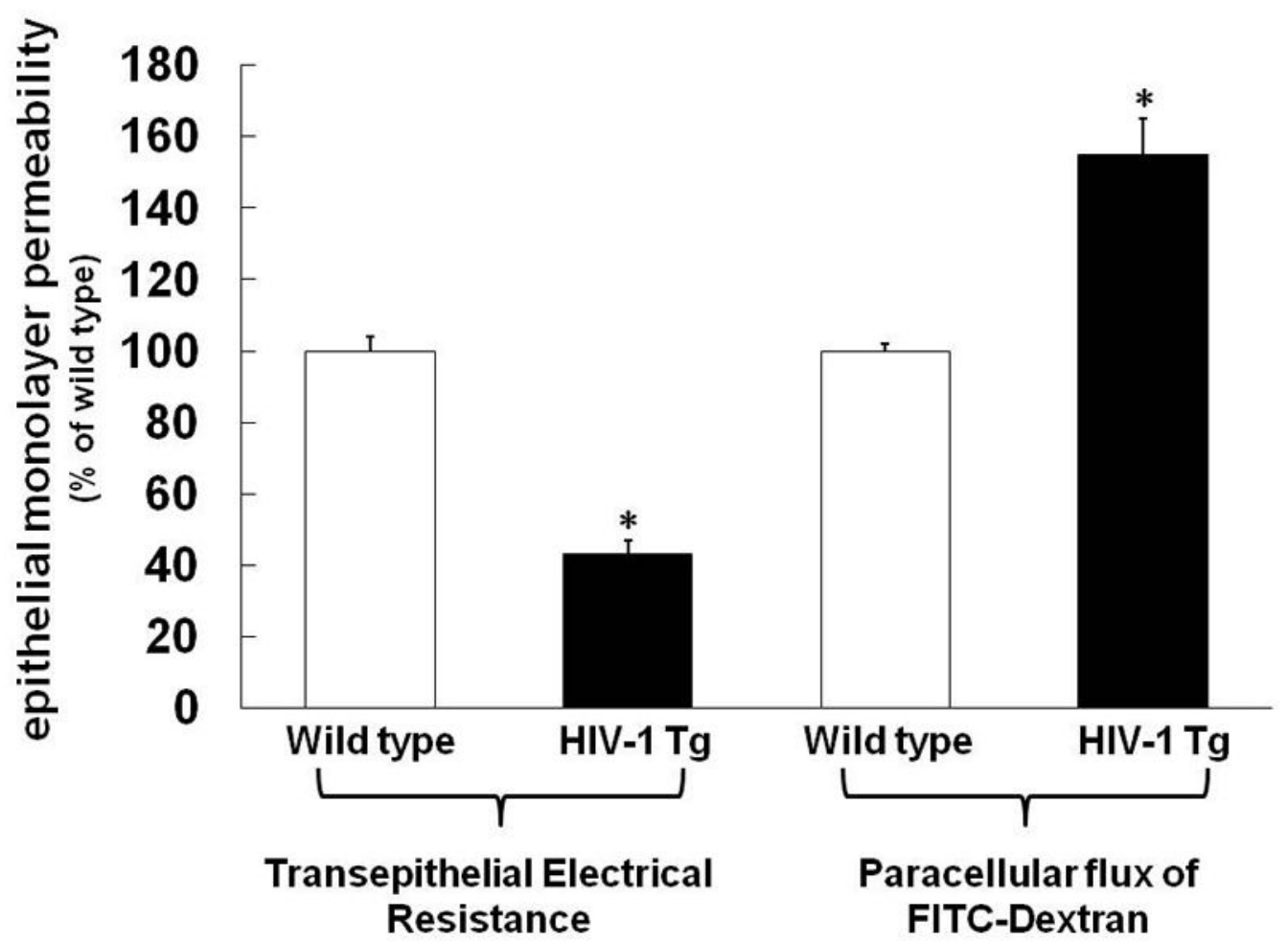

Figure 1. HIV-1 transgene expression impairs alveolar epithelial barrier function, with comparable effects on both transepithelial electrical resistance (TEER) and paracellular permeability of FITC-Dextran

Alveolar epithelial cells were isolated from wild type (WT) and HIV-1 transgenic (Tg) rats fed the isocaloric liquid diet \pm alcohol for $12 \mathrm{wks}$ and cultured in transwell plates for 7 days to establish monolayers. The transepithelial electrical resistance (TEER) and the paracellular flux of FITC-Dextran were determined as described in the Methods. Each value represents the mean \pm SEM of 4 determinations. $* \mathrm{P}<0.05$ compared to wild type. 


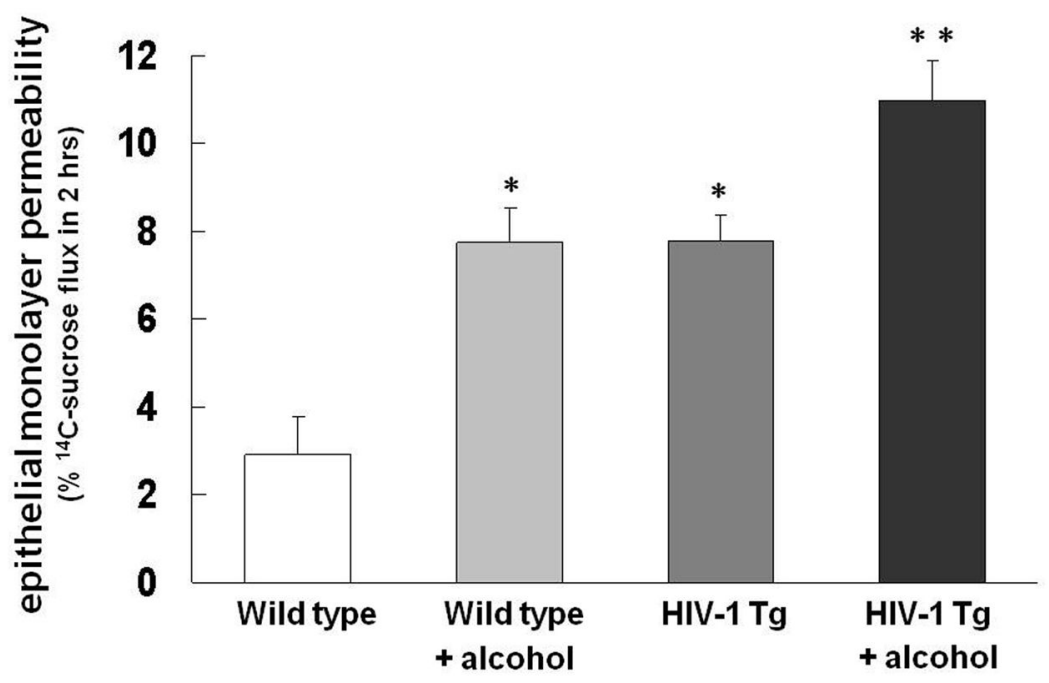

Figure 2. Chronic alcohol ingestion exacerbates barrier dysfunction in alveolar epithelial monolayers derived from HIV-1 transgenic rats

Alveolar epithelial cells were isolated from wild type (WT) and HIV-1 transgenic (Tg) rats fed the isocaloric liquid diet \pm alcohol for $12 \mathrm{wks}$ and cultured in transwell plates for 7 days to establish monolayers; permeability (in this case as reflected by transepithelial flux of ${ }^{14} \mathrm{C}$ sucrose in $2 \mathrm{hrs}$ ) was then determined as described in the Methods. Each value represents the mean \pm SEM of the flux $(\%)$ of ${ }^{14} \mathrm{C}$-sucrose in $2 \mathrm{hrs}$ in $6-11$ monolayers. $* \mathrm{P}<0.05$ increased permeability compared to alveolar epithelial monolayers derived from wild type rats not fed alcohol. $* * \mathrm{P}<0.05$ increased permeability compared to alveolar epithelial monolayers derived from wild type rats fed alcohol and to HIV-1 Tg rats not fed alcohol. 


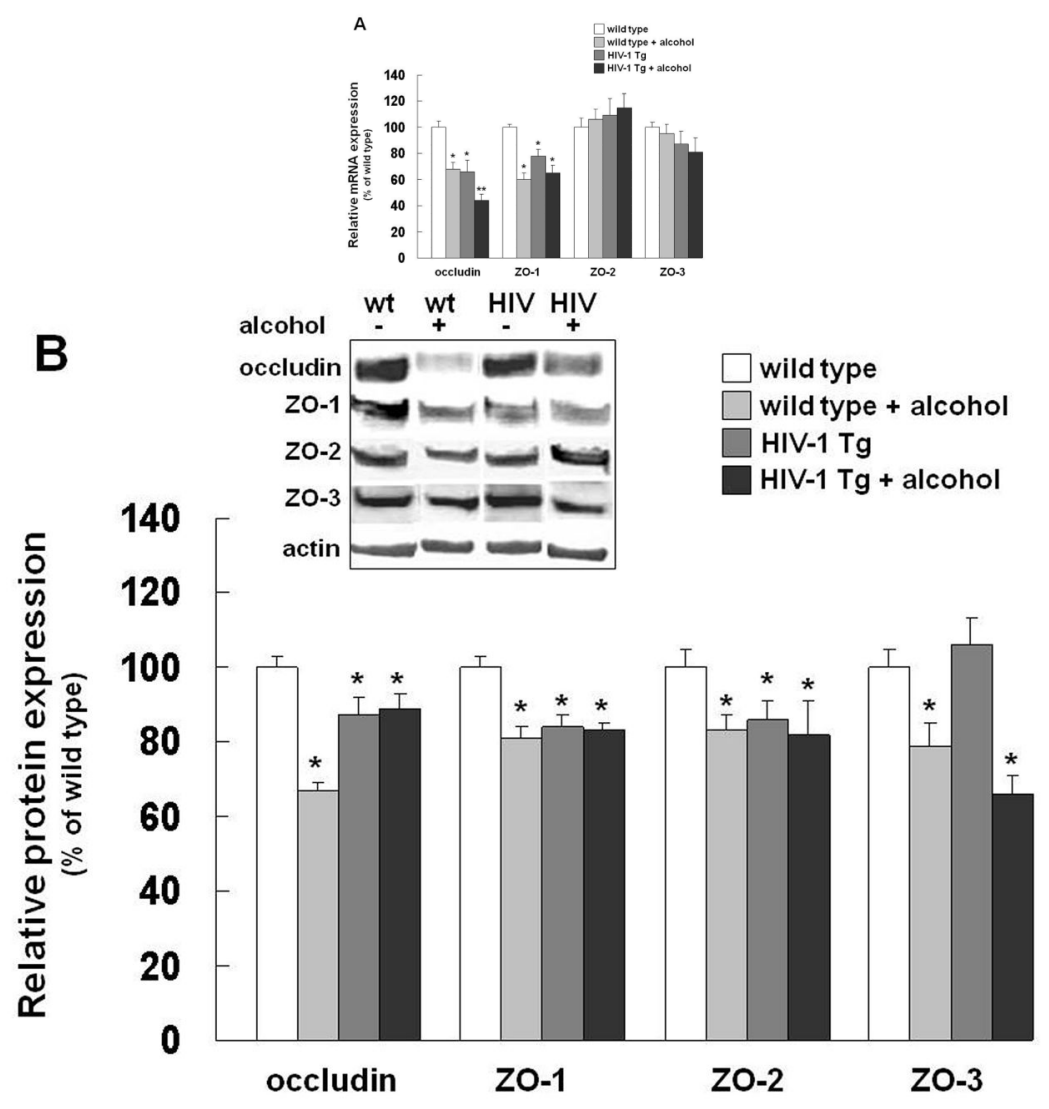

Figure 3. Chronic alcohol ingestion or HIV-1 transgene expression altered the expression of occludin and zonula occludens (tight junction proteins) in cultured alveolar epithelial monolayers, but there was no evidence that these effects were additive

Primary alveolar epithelial type cells were isolated and cultured for 6-7 days as in Figure 1. The gene and protein expressions of the tight junction proteins occludin, $\mathrm{ZO}-1, \mathrm{ZO}-2$ and ZO-3 were determined by RT-PCR and western blot analyses, respectively, as described in the Methods. Panel A shows the relative gene expression for each of these four tight junction proteins, and in each case is normalized to the expression monolayers derived from wild type rats. Each value represents the mean \pm SEM; $n=4-6$. Panel $B$ shows the protein expression for each of these four tight junction proteins expressed quantitatively as the relative densitometry of the individual tight junction protein bands compared to the actin bands in each sample, and in each case is normalized to the expression in monolayers derived from wild type rats. Each value represents the mean \pm SEM; $n=3-7$. Representative western blots for each of the tight junction proteins and actin are shown above the summary data. $* \mathrm{P}<0.05$ decreased expression compared to wild type rats not fed alcohol. $* * \mathrm{P}<0.05$ decreased expression compared to wild type rats fed alcohol and to HIV-1 Tg rats not fed alcohol. 


\section{A Occludin}

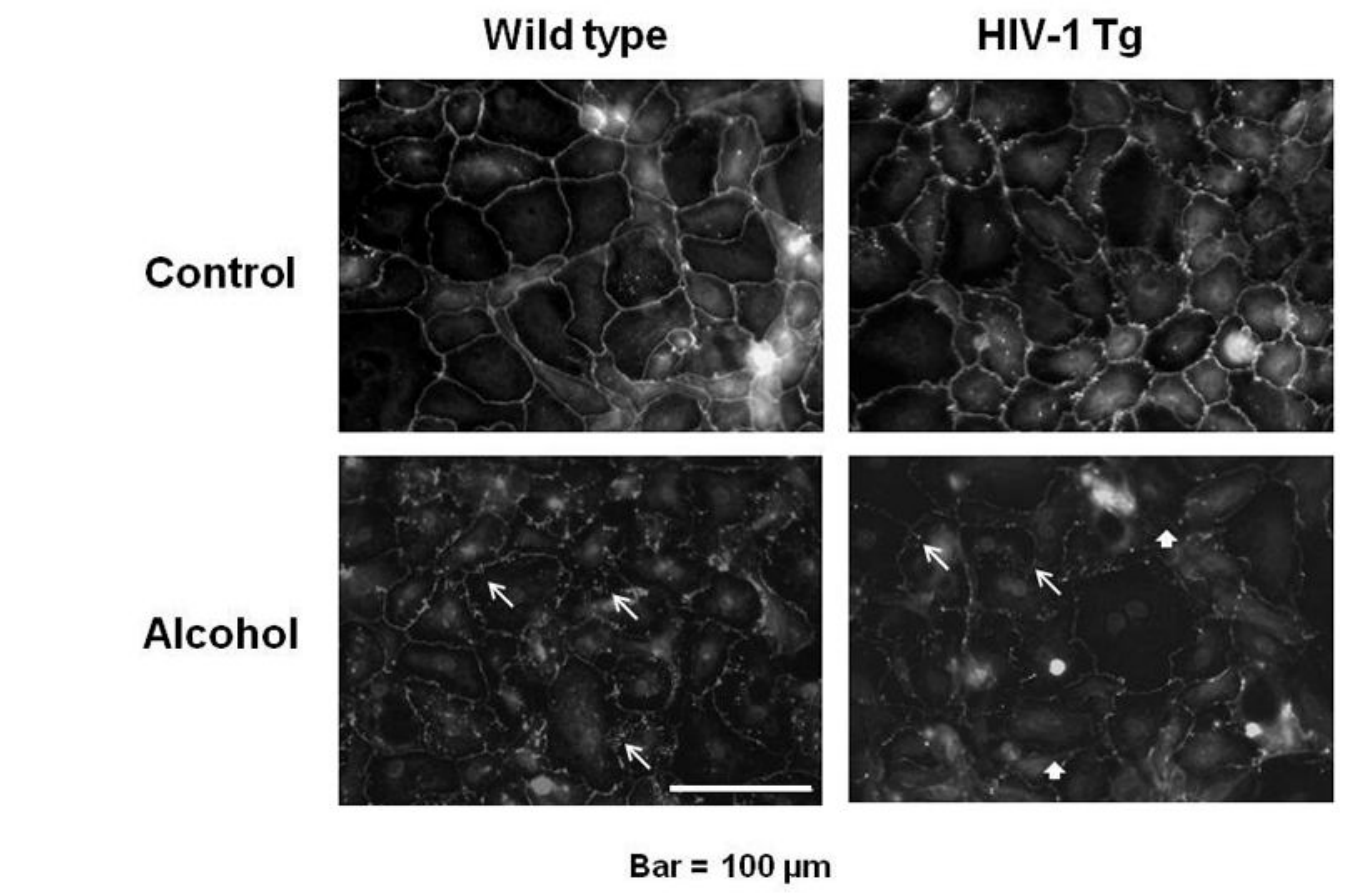

B ZO-1
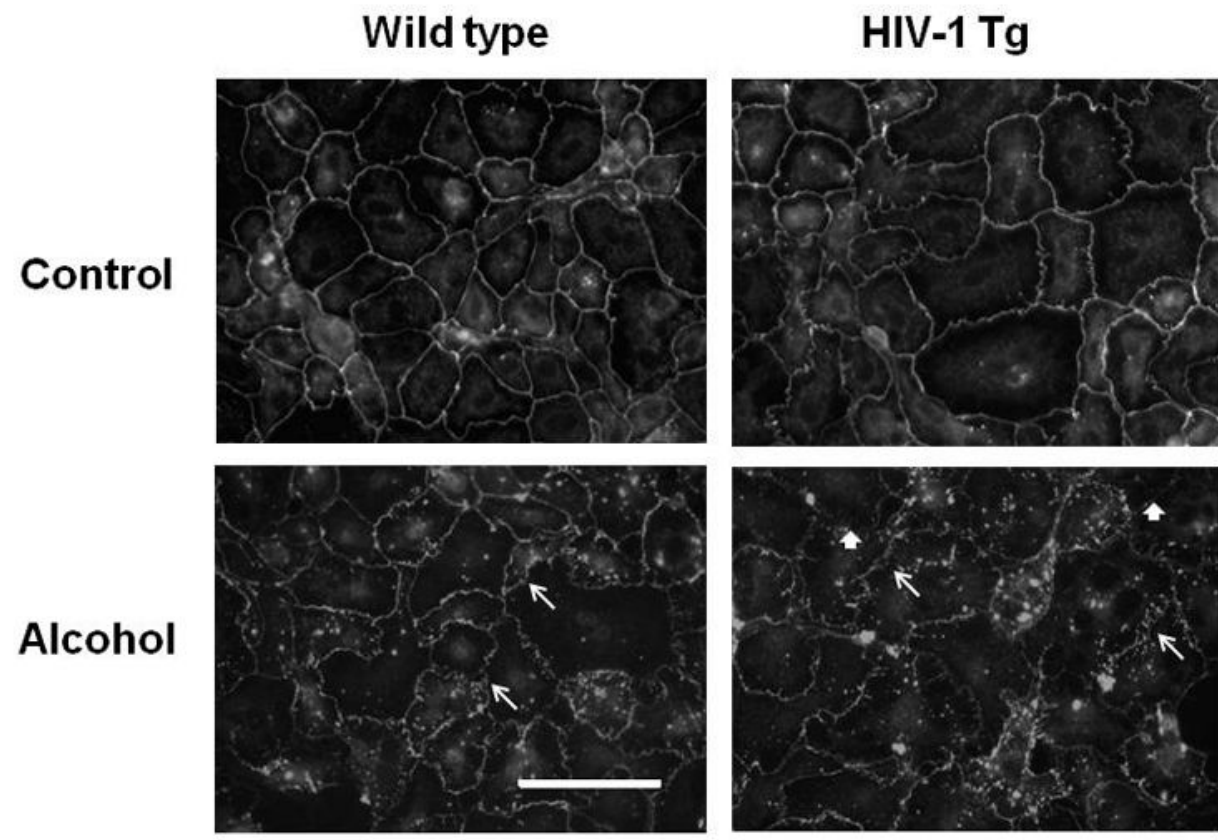

Bar $=100 \mu \mathrm{m}$

Figure 4. Chronic alcohol ingestion or HIV-1 transgene expression altered the membrane localization of occludin and zonula occludens- 1 in cultured alveolar epithelial monolayers 
Alveolar epithelial cells were isolated and cultured on coverslips for 7 days; membrane localization of occludin (Panel A) and ZO-1(Panel B) expression was then examined qualitatively by fluorescent immunocytochemistry as described in the Methods. Bar $=100$ $\mu \mathrm{m}$. 
A

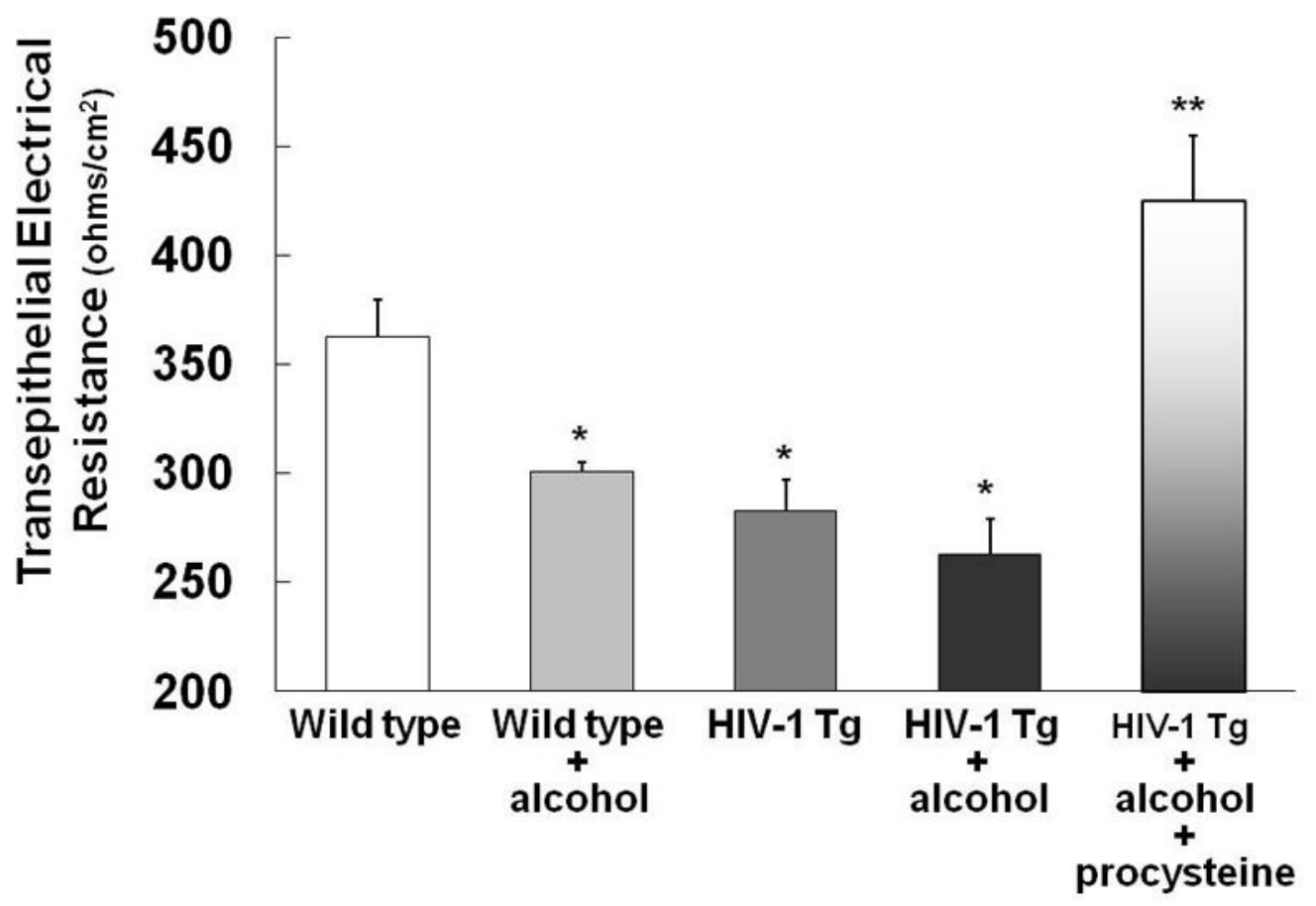

$\mathbf{B}$

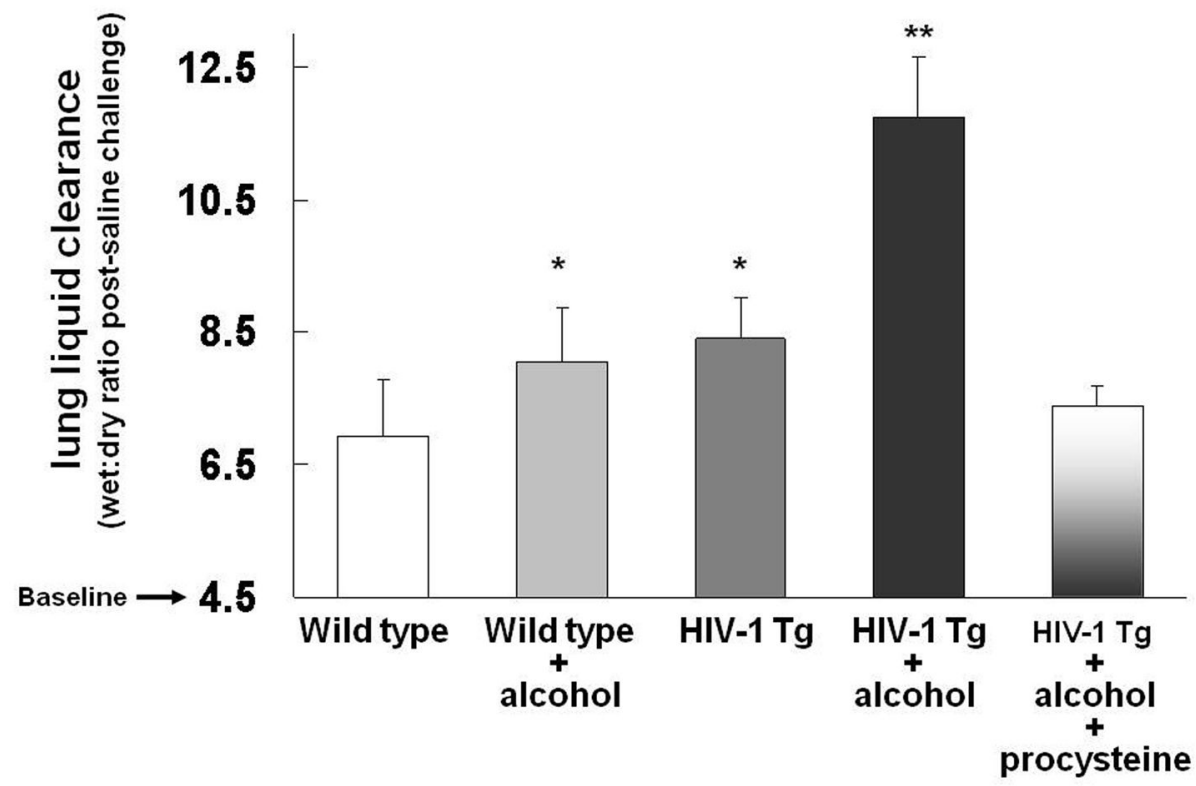

Figure 5. Dietary supplementation with the glutathione precursor procysteine restored alveolar epithelial barrier function in alcohol-fed HIV-1 transgenic rats

Wild type (WT) rats and HIV-1 transgenic (Tg) rats were fed the isocaloric liquid diet \pm alcohol for $12 \mathrm{wks}$; some HIV-1 Tg rats had their alcohol diets supplemented with procysteine (0.35\%; see Methods) and alveolar epithelial barrier function was assessed.

Panel A shows the barrier properties of alveolar epithelial monolayers after 7 days in culture 
in transwells as previously described; in these experiments barrier function was determined by quantifying transepithelial electrical resistance (TEER). Each value represents the mean \pm SEM of monolayers derived from $5-11$ rats. * $\mathrm{P}<0.05$ decreased TEER compared to wild type rats not fed alcohol. ** $\mathrm{P}<0.05$ increased TEER compared to wild type rats not fed alcohol. Panel B shows alveolar epithelial barrier function in vivo as quantified by the clearance of an intratracheal saline challenge (a relatively lower wet:dry ratio reflects increased fluid clearance) as described in the Methods. Each value represents the mean \pm SEM of 5-11 rats. ${ }^{*} \mathrm{P}<0.05$ decreased lung liquid clearance (increased wet:dry ratio) compared to wild type rats not fed alcohol. ** $\mathrm{P}<0.05$ decreased lung liquid clearance (increased wet:dry ratio) compared to wild type rats fed alcohol and to HIV-1 Tg rats not fed alcohol. 

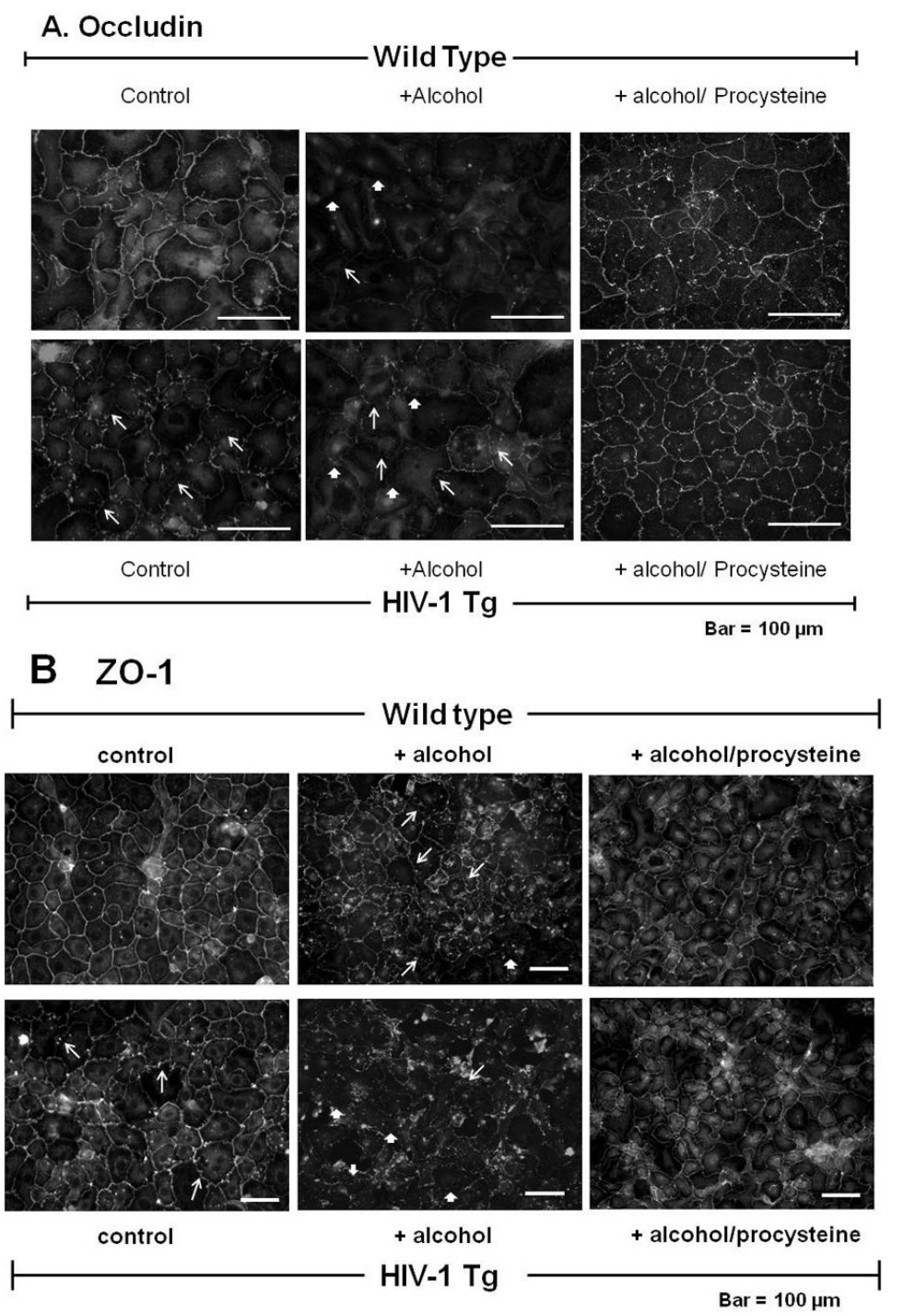

Figure 6. Dietary supplementation with procysteine qualitatively improved the membrane localization of occludin and zonula occludens-1 in cultured alveolar epithelial monolayers from alcohol-fed rats \pm HIV-1 transgene expression

Alveolar epithelial cells were isolated and cultured as same as Figure 4; monolayers were then examined qualitatively by fluorescent immunocytochemistry as in Figure 4 for membrane localization of occludin (Panel A) and ZO-1 (Panel B). Occludin and ZO-1 expression in alcohol fed rats or HIV $-1 \mathrm{Tg}$ rats \pm alcohol showed a significant decreasing staining in cell-cell border (arrowhead) and punctuate, less uniform staining (arrows). Bar $=100 \mu \mathrm{m}$. 


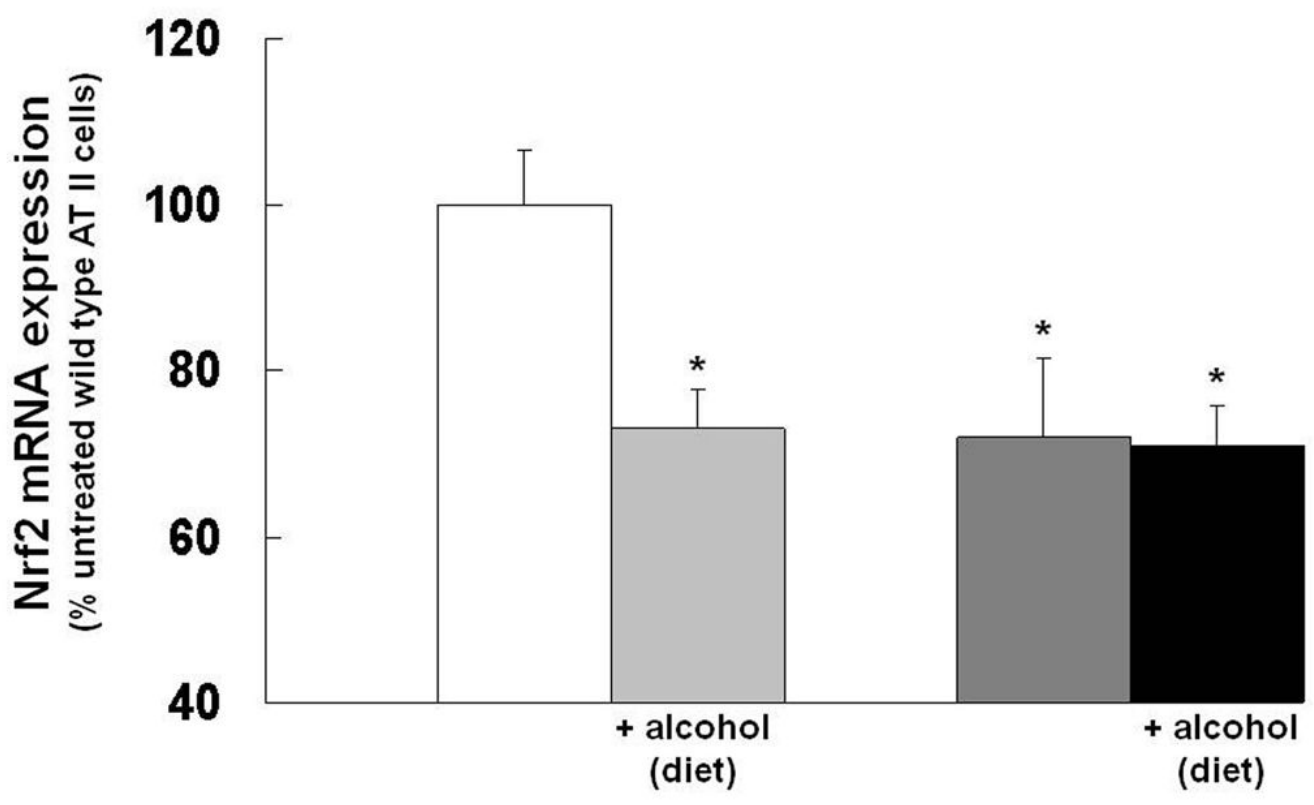

Wild type

HIV-1 Tg

B

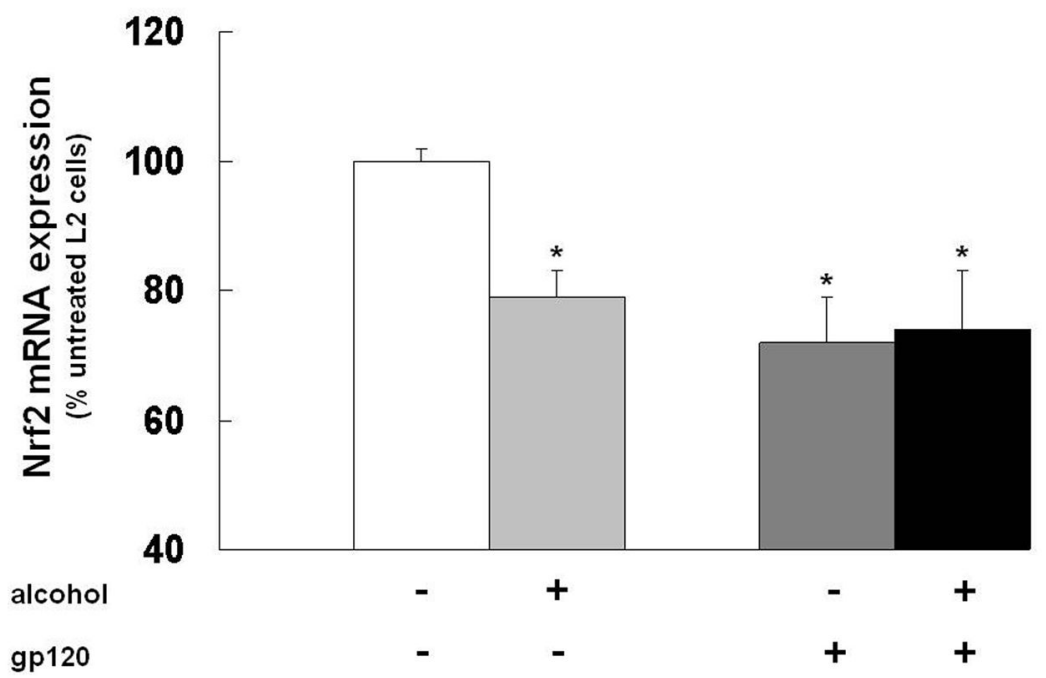

Figure 7. Chronic alcohol ingestion or HIV-1 transgene expression in vivo, or exposure to alcohol or the HIV-1-related protein gp120 in vitro, decreased gene expression of $\mathrm{Nrf} 2$ in lung epithelial cells

Panel A shows the relative gene expression of Nrf2 (as determined by quantitative PCR as described in the Methods) in freshly isolated alveolar epithelial cells from wild type (WT) and HIV-1 transgenic ( $\mathrm{Tg}$ ) rats fed the isocaloric liquid diet \pm alcohol for $12 \mathrm{wks}$. Data shown represent the mean \pm SEM; $\mathrm{N}=5-6$ rats in each group. $* \mathrm{P}<0.05$ decreased compared to wild type rats not fed alcohol. Panel B shows the relative gene expression of 
Nrf2 in L2 cells (a rat lung epithelial cell line) treated with the HIV-1-related protein gp120 $(100 \mathrm{ng} / \mathrm{ml})$, alcohol $(0.1 \% \mathrm{w} / \mathrm{v})$, or a combination of gp120 and alcohol for 3 days. Data shown represent the mean \pm SEM; $\mathrm{n}=5-6$ determinations in each group. $* \mathrm{P}<0.05$ decreased compared to untreated L2 cells. 


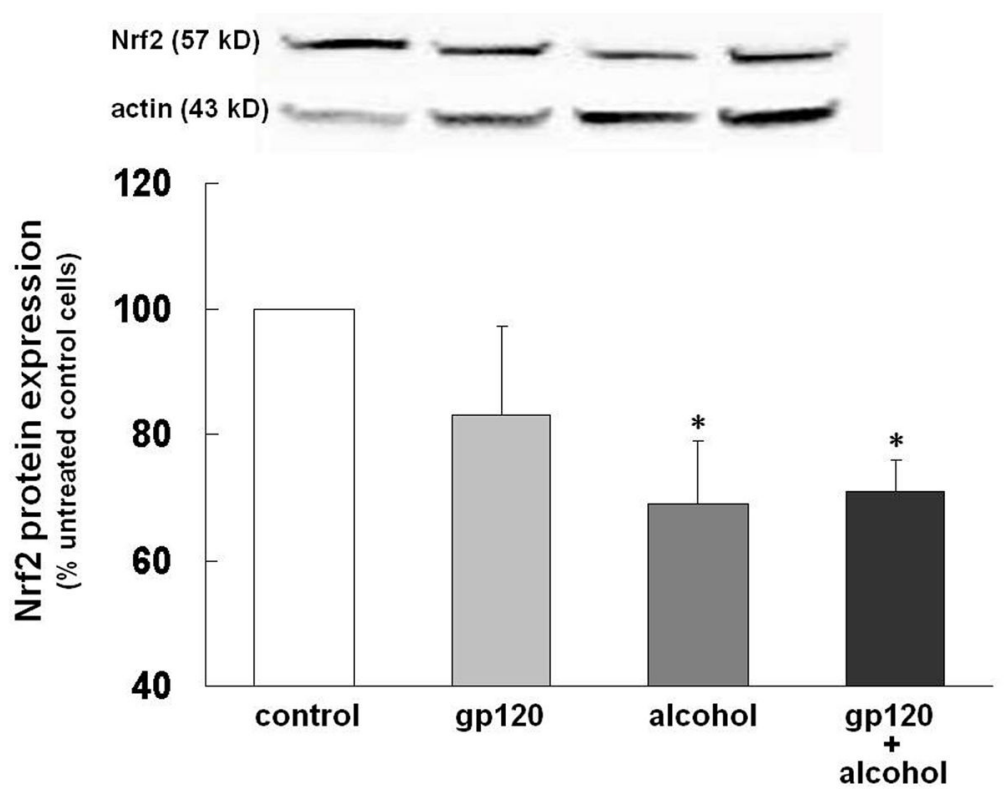

Figure 8. Exposure to alcohol or the HIV-1-related protein gp120 in vitro decreased protein expression of $\mathrm{Nrf} 2$ in lung epithelial cells

Rat lung epithelial cell line, L2 cells were treated with gp120 and alcohol for 3 days in identical fashion as cells in Figure 7, panel B. Nrf2 protein expression was determined by western blot analysis as described in the Methods and expressed quantitatively as relative densitometry of the Nrf2 bands compared to the actin bands in each sample. Data shown represent the mean \pm SEM of 5-6 determinations per group normalized to the mean relative densitometry in bands from untreated L2 cells. * $\mathrm{P}<0.05$ decreased compared to untreated L2 cells. A representative western blot showing the bands for Nrf2 and actin in each group are shown above the summary data. 